\title{
Development of erosion risk map using fuzzy logic approach
}

\author{
Manyuk Fauzi ${ }^{1, *}$, Imam Suprayogi ${ }^{1}$, Sigit Sutikno $^{1}$, Ari Sandhyavitri ${ }^{1}$ and Eko Riyawan ${ }^{1}$ \\ ${ }^{1}$ Civil Engineering Department, Universitas Riau, 28293 Riau, Indonesia
}

\begin{abstract}
Erosion-hazard assessment is an important aspect in the management of a river basin such as Siak River Basin, Riau Province, Indonesia. This study presents an application of fuzzy logic approach to develop erosion risk map based on geographic information system. Fuzzy logic is a computing approach based on "degrees of truth" rather than the usual "true or false" ( 1 or 0 ) Boolean logic on which the modern computer is based. The results of the erosion risk map were verified by using field measurements. The verification result shows that the parameter of soil-erodibility $(\mathrm{K})$ indicates a good agreement with field measurement data. The classification of soil-erodibility $(\mathrm{K})$ as the result of validation were: very low $(0.0$ $0.1)$, medium (0.21-0.32), high (0.44-0.55) and very high (0.56-0.64). The results obtained from this study show that the erosion risk map of Siak River Basin were dominantly classified as medium level which cover about $68.54 \%$. The other classifications were high and very low erosion level which cover about $28.84 \%$ and $2.61 \%$ respectively.
\end{abstract}

\section{Introduction}

Siak river region is one of the major rivers that is included in the national strategic river criteria (Minister Regulation No. 04/PRT/M/2015). The criteria of national strategic has the following parameters: a) the potential of water resources in the relevant river area is bigger or equal to $20 \%$ of the potential water-resource in the province; b) the number of resources sectors in the relevant-river basin is at least 16 (sixteen) sectors; and the number of population in the basin is at least $30 \%$ (thirty percent) of the total province population; d) the negative impact due to the destructive force of water to economic growth resulting in economic losses is at least $1 \%$ of gross regional domestic product of the province.

In 2003, the palm-oil plantation area dominated the land cover in upstream of Siak river basin (Tapung River Basin), which had the area of $76,249.6$ ha or $44.80 \%$. However the area of forest was only $15,624.36$ ha or $9.18 \%$ of the total land area. In 2007 , the forest area decreased to $7,352.64$ ha or $4.32 \%$. There were additional forest area in 2012 to $12,186.32$ ha, or $7.16 \%$. If the land use change is allowed continuously, this activity will have many impacts on the water quality and quantity of the Siak River Basin, especially in the upper watershed (Tapung Basin). In addition to this problem, the impact of the land use changes also contributed to the potential soil erosion. Thus, effort is needed to build a map of potential erosion under conditions of existing land use. The application of soft computing approach is very powerfull to develop erosion risk map based on geographic information system [1].

In the last decade, the soft computing model as a branch of artificial intelligence was introduced as a forecasting tool such as knowledge-based systems, expert systems, fuzzy logic, artificial neural network and genetic algorithms [1]. Applications of fuzzy-logic soft computing models particularly (fuzzy logic) in water resource management efforts have been carried out in various countries, such as research on the fluctuation of groundwater flow simulation in India [2], the study of erosion by using GIS and fuzzy logic in Turkey [3], the study of optimal water network using fuzzy logic in Singapore [4], and the research about development of erosion risk map using fuzzy logic method in combination with geographic information system (GIS) [5]. The input data for this model were soil maps, topographic maps and density-flow data. The data processing were conducted by decision-making system using the fuzzy-logic Mamdani type models with triangular representation. The research results proved that the model provided an effective description of erosion-risk map.

\section{Method}

\subsection{Research location}

Siak River basin is located in Riau Province, Indonesia with the area of $1,481,499.25$ ha. Geographically the Siak river basin is in the position between $100^{\circ} 28^{\prime}-102^{\circ}$ $12^{\prime}$ East Longitude and $0^{0} 20^{\prime}-1^{0} 16^{\prime}$ North Latitude.

\subsection{Fuzzy logic}

The system of fuzzy membership function has a very important role to present a problem [6-7]. Membership

Corresponding author: manyu_fauzi@yahoo.com 
function is a curve that shows the mapping of points of input data into membership values (often called the degrees of membership) which has the interval between 0 and 1 . One way that can be used to get the value of membership is through the function-approach. There are several functions that can be used include:

a. Linear representation

In the linear representation, mapping input to the degree of membership described as a straight line. This is the simplest form and be a good choice to approach a concept that is less clear. The linear state of fuzzy set consists of two state: linear-rise and linear-down. In the linear-rise, hike begins at the set of domain values that have a membership degree of 0 (zero) moves to the right towards the domain value that has a higher degree of membership with membership functions:

$$
\mu[x]=\left\{\begin{array}{lc}
0 & x \leq a \\
(x-a) /(b-a) & a \leq x \leq b \\
1 & x \geq b
\end{array}\right.
$$

While the linear down, straight line starting from the value of the domain with the highest degree of membership on the left side, then move down to the domain values that have lower degrees of membership with membership functions.

$$
\mu[x]= \begin{cases}1 & x \leq a \\ (b-x) /(b-a) & a \leq x \leq b \\ 0 & x \geq b\end{cases}
$$

b. Triangle representation

Triangular membership function is characterized by the presence of three (3) parameters $\{a, b, c\}$ which will determine the $\mathrm{x}$ coordinate of the three angles. This curve is basically a combination of the two lines (linear). The equation for this triangular shape is:

$$
\mu[x]= \begin{cases}0 & x \leq a \text { atau } x \geq c \\ (x-a) /(b-a) & a \leq x \leq b \\ (c-x) /(c-b) & b \leq x \leq c\end{cases}
$$

c. Trapezoidal-representations

Trapezoidal curve is essentially like a triangular shape, with some points that have a value of membership 1 . The equation for a trapezoid curve are:

$$
\mu[x]= \begin{cases}0 & x \leq a \text { atau } x \geq d \\ (x-a) /(b-a) & a \leq x \leq b \\ 1 & b \leq x \leq c \\ (d-x) /(d-c) & c \leq x \leq d\end{cases}
$$

Fuzzy inference system is a process of formulating a mapping from a given input to an output using fuzzy logic. This system involves the fuzzy logic and the components therein such as membership functions, logic operations and if-then rules. In general, there are two kinds of fuzzy inference systems that can be implemented, namely the Mamdani Type and the Sugeno Type. According to [8]; [9], there are four phases to obtain output in the type of Mamdani Fuzzy Inference System, namely:

1. Comparing the input variables with membership functions in the antecedent ("because" part) to obtain the membership value of each linguistic variables. This process can be established by comparing the input variables and membership functions to obtain the membership value of each linguistic variables.

2. Combine all input variables by applying the t-norm. T-norm is sliced operations on fuzzy sets. System rules are used is min with liaison "AND". Operating results with the operator "AND" is expressed as $\alpha$-predicate.

3. Generate consequences ("due" part) qualified or each rule based on weight. The set composition of the fuzzyset rules is a process that states the output of each rule to be combined together into a fuzzy set. Each rule can be written in the form of the following languages:

"If the antecedent then the consequent" or it can also be defined as follows: If $\mathrm{x} 1$ is $\mathrm{A} 1$ AND...AND xn is An THEN y is B. "If-Then" form is a form of expression based-on reasoning system that consists of numbers (r) of fuzzy rules.

4. Aggregation of all parts of the consequences. Forms part of the consequences of the process of aggregation is called "defuzzification". "Defuzzification" is a convertible model of the form of fuzzy-value into the amount / value more precise. One of the method is "the centroid method" with a mathematical formulation in the following equation:

$$
z=\frac{\int_{a}^{b} x \mu_{A}(x) d x}{\int_{a}^{b} \mu_{A}(x) d x}
$$

where $z$ defuzzification-value; $x$ fuzzy members set A; and $\mathrm{uA}(\mathrm{x})$ the degree of membership of an element $\mathrm{x}$ in a set A. Input from "defuzzification" process is a fuzzyset obtained from the composition of fuzzy-rules, whereas the resulting output is a fuzzy set of the domain.

\section{Result and discussion}

\subsection{Analysis of soil erodibility value (K)}

Based on geological and soil unit maps, the upstream of Siak River Basin consists of several orders of soil; such as inceptisol, ultisol, oxisol, entisols and histosol. Inceptisol order consists of several types namely dystrudept, dystropepts, and endoaquepts. Ultisol order consists of great group (equivalent) of land that is hapludults, kandiudults, tropodults. Order Oxisol soil consists of one type of soil that is hapludox. Land entisols order consists of one type of soil that is tropofluvents. Then ground histosol order consists of several types of ground (great group) namely haplosaprits, troposaprits and tropohemists. The description soil maps of upstream Siak river basin is presented in Fig. 1. 


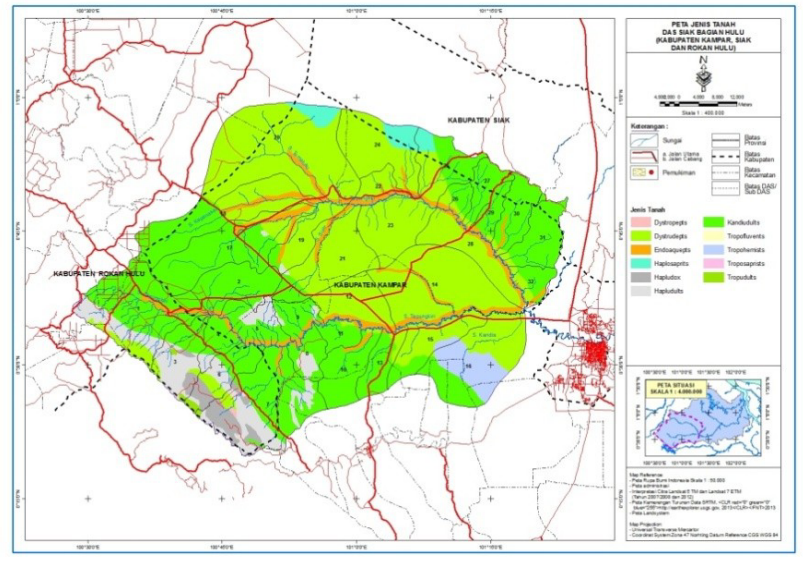

Fig. 1. Soil maps of upstream Siak Basin

Table 1 shows that the erodibility of the upstream section of Siak river basin is included in the classification between low (0.11 to 0.20$)$ and medium (0.21 to 0.32$)$. In principle, soil properties affecting soil erodibility are soil properties that affect the infiltration rate, permeability, soil's capacity to hold water, and soil properties that affect resistance of soil structure against dispersion and attenuation beads of runoff. The soil properties are texture, structure, organic matter, soil nature and fertility.

Table 1. Value of weighted erodibility $(\mathrm{K})$

\begin{tabular}{|c|c|c|c|}
\hline $\begin{array}{c}\text { ID Number of } \\
\text { Tapung Kiri Sub } \\
\text { Basin }\end{array}$ & $\begin{array}{c}\text { Rated } \\
\text { K }\end{array}$ & $\begin{array}{l}\text { ID Number of } \\
\text { Tapung Kanan } \\
\text { Sub Basin }\end{array}$ & $\begin{array}{c}\text { Rated } \\
\mathbf{K}\end{array}$ \\
\hline 1 & 0.254 & 17 & 0.248 \\
\hline 2 & 0.251 & 18 & 0.238 \\
\hline 3 & 0.238 & 19 & 0.221 \\
\hline 4 & 0.258 & 20 & 0.271 \\
\hline 5 & 0.265 & 21 & 0.222 \\
\hline 6 & 0.227 & 22 & 0.233 \\
\hline 7 & 0.231 & 23 & 0.211 \\
\hline 8 & 0.259 & 24 & 0.222 \\
\hline 9 & 0.258 & 25 & 0.239 \\
\hline 10 & 0.251 & 26 & 0.244 \\
\hline 11 & 0.251 & 27 & 0.249 \\
\hline 12 & 0.221 & 28 & 0.223 \\
\hline 13 & 0.244 & 29 & 0.251 \\
\hline 14 & 0.219 & 30 & 0.251 \\
\hline 15 & 0.110 & 31 & 0.249 \\
\hline 16 & 0.239 & 32 & 0.243 \\
\hline
\end{tabular}

\subsection{Slope analysis (LS)}

The length and slope were obtained from the [10], then were multiplied with the slope comprehensive classification.

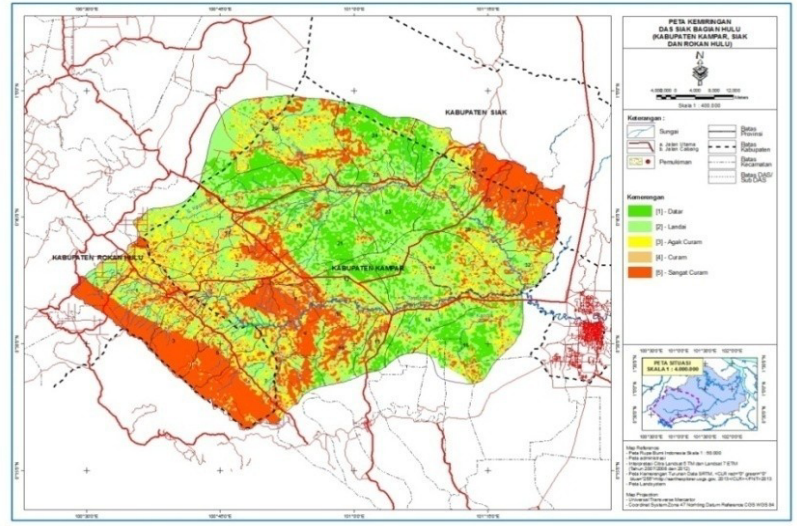

Fig. 2. Slope of upstream Siak River Basin

Table 2. Classification of slopes

\begin{tabular}{|c|c|c|}
\hline Class & Slope (\%) & Class Description \\
\hline I & $0-8$ & Flat \\
\hline II & $8-15$ & Sloping \\
\hline III & $15-25$ & Somewaht steep \\
\hline IV & $25-45$ & Steep \\
\hline V & $>45$ & Extremely steep \\
\hline
\end{tabular}

Table 3. Percentage area of class slopes

\begin{tabular}{|c|c|c|}
\hline Class & Slope (\%) & Percentage (\%) \\
\hline I & $71,359,556$ & 15.36 \\
\hline II & $153,523,425$ & 33.04 \\
\hline III & $71,775,121$ & 15.45 \\
\hline IV & $53,231,838$ & 11.45 \\
\hline V & $114,775,492$ & 24.70 \\
\hline Total & $464,665,432$ & 100.00 \\
\hline
\end{tabular}

Table 4. Value of weighted slope (LS)

\begin{tabular}{|c|c|c|c|}
\hline $\begin{array}{c}\text { ID Number of } \\
\text { Tapung Kiri Sub } \\
\text { Basin }\end{array}$ & $\begin{array}{c}\text { Rated } \\
\text { LS }\end{array}$ & $\begin{array}{c}\text { ID Number of } \\
\text { Tapung Kanan } \\
\text { Sub Basin }\end{array}$ & $\begin{array}{c}\text { Rated } \\
\text { LS }\end{array}$ \\
\hline 1 & 5.726 & 17 & 4.035 \\
\hline 2 & 4.620 & 18 & 2.514 \\
\hline 3 & 7.390 & 19 & 3.615 \\
\hline 4 & 4.790 & 20 & 3.171 \\
\hline 5 & 6.459 & 21 & 2.425 \\
\hline 6 & 6.488 & 22 & 2.573 \\
\hline 7 & 6.652 & 23 & 1.358 \\
\hline 8 & 7.346 & 24 & 2.357 \\
\hline 9 & 8.318 & 25 & 2.427 \\
\hline 10 & 5.202 & 26 & 2.910 \\
\hline 11 & 5.786 & 27 & 7.654 \\
\hline 12 & 2.459 & 28 & 2.787 \\
\hline 13 & 3.353 & 29 & 6.133 \\
\hline 14 & 2.569 & 30 & 8.039 \\
\hline 15 & 2.239 & 31 & 7.764 \\
\hline 16 & 2.470 & 32 & 3.440 \\
\hline & & &
\end{tabular}

The classification of slope can be seen in Table 2, which were classified in to 5 (five) classes of slope. Table 3 shows that the slope on upstream Siak river basin is dominated as ramps $(33.04 \%)$. To grade the next slope is 
very steep $(>45 \%)$ with an percentage $24.70 \%$. Small slope will give more opportunities to rainfall for infiltration. In conjunction with the large loss of land, the small slope will reduce runoff, so the ability to erode and sediment transport to be low.

\subsection{Density index (Dd)}

Results of the map data processing in upstream Siak river basin section were used to determine the flow or drainage density which was calculated from the ratio of the total length of the river network. The density of the flow of the river is an index number that indicates the number of tributaries in a watershed. Description density maps of upastream Siak river basin and the value of weighted density index are presented in Fig. 3 and Table 5 respectively.

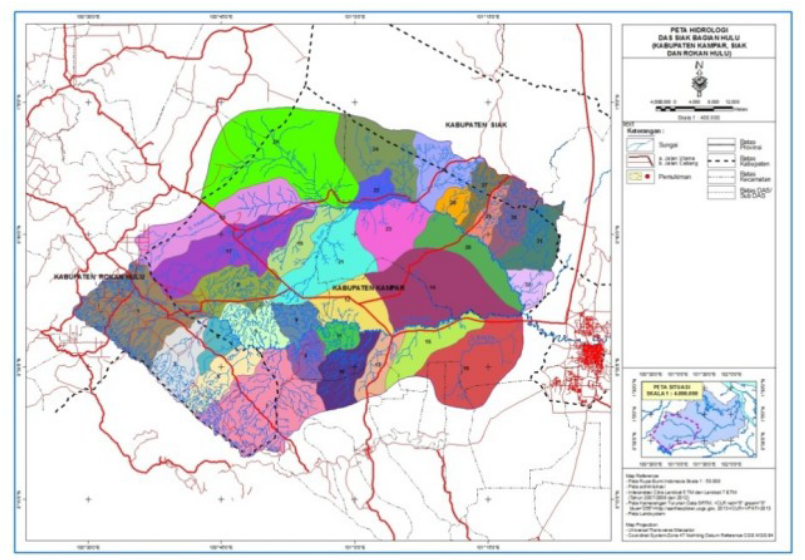

Fig. 3. Density index maps upstream of Siak Basin

The density of the river flow that illustrates the storage capacity of the surface water in basins such as lakes, marshes and rivers that flow in a watershed. The higher density level of the river flow, the more water can be absorbed in the river bodies.

Table 5. Classification of flow density index

\begin{tabular}{|c|c|c|}
\hline Class & $\begin{array}{c}\text { Flow Density Index } \\
\left(\mathbf{k m} / \mathbf{k m}^{\mathbf{2}}\right)\end{array}$ & Class Description \\
\hline I & $<0.25$ & Low \\
\hline II & $0.25-10$ & Moderate \\
\hline III & $10-25$ & High \\
\hline IV & $>25$ & Very High \\
\hline
\end{tabular}

\subsection{Fuzzy inference system algorithm}

The method used in this study was the fuzzy inference system, which the stages of these methods are as followings.

1. Establish the variable input and output variables Input variables used are erodibility $(\mathrm{K})$, length and slope (LS) and current density (Dd), while the output variable is the index of the risk of erosion.

2. Establish a fuzzy set. Fuzzy set was formed for each variable as follows:

a. The Variable Erodibility forming three fuzzy set, i.e. low, medium, and high.

Table 7. The percentage of erosion risk class area b. The Variable Slope of forming three fuzzy set, i.e. low, medium, and high.

c. The Variable Density Flow forming three fuzzy set, i.e. low, medium, and high.

3. Establish a set of discourse universe

The universe of discourse of each variable is the range of possible values of the input variable data. Universe of discourse based on [5] can be shown as in Table 6.

Table 6. Fuzzy variables

\begin{tabular}{|c|c|c|}
\hline Functions & Variables & Classification \\
\hline \multirow{3}{*}{ Input } & Erodibility & $\begin{array}{c}\text { Low }[0-0.5] \\
\text { Moderate }[0.25-0.75] \\
\text { High }[0.5-1]\end{array}$ \\
\hline & Slope/Tilt & $\begin{array}{c}\text { Low [0-0.5] } \\
\text { Moderate [0.25-0.75] } \\
\text { High [0.5-1] }\end{array}$ \\
\hline & Density Flow & $\begin{array}{c}\text { Low [0-0.5] } \\
\text { Moderate [0.25-0.75] } \\
\text { High [0.5-1] }\end{array}$ \\
\hline Output & $\begin{array}{l}\text { Erotion Risk } \\
\text { Index }\end{array}$ & $\begin{array}{c}\text { Very Low }[0-0.25] \\
\text { Low }[0-0.5] \\
\text { Moderate }[0.25-0.75] \\
\text { High }[0.5-1]\end{array}$ \\
\hline
\end{tabular}

\subsection{Erotion risk map of fuzzy logic result}

Results that were obtained from the decision making process was erosion risk level classification of each macro basin (ID Number of Sub Basin). The classification described very low, medium and high grade. By using those erosion risk levels, the erosion risk can be mapped. The results of this mapping were shown in Fig. 4.

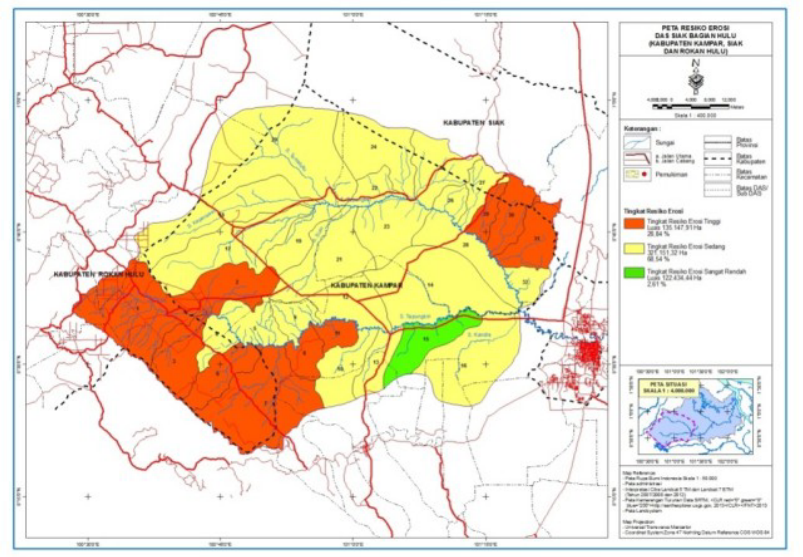

Fig. 4. Risks erosion maps in upstream of Siak Basin

Fig. 4 shows that the erosion risk in upstream of Siak river basin is dominated with the moderate level of erosion risk which is about $321,151,320$ ha (68.54\%). For high level of risk erosion with extensive 135,147,910 ha $(28.84 \%)$ is more predominant in the Tapung Kiri sub basin. While, the attrition rate is very low with an area of $122,434,440$ hectares $(2.61 \%)$. More details about the area of erosion risk class can be seen in Table 7 . 


\begin{tabular}{|c|c|c|}
\hline Erosion Risk Class & Area (Ha) & Percentage (\%) \\
\hline Very Low & $12,143,440$ & 2,61 \\
\hline Moderate & $318,497,176$ & 68,54 \\
\hline High & $134,024,999$ & 28.84 \\
\hline Total & $464,665,432$ & 100.00 \\
\hline
\end{tabular}

According to [5] the input variables such as soil erodibility, slope and stream density is the decisive factor for the risk of soil erosion. Based on the results of erosion risk map and the results of validation studies the risk of erosion in upstream of Siak basin indicates that the variable erodibility, slope and stream density showed as factors that influence the risk of soil erosion.

Overall the rate of erosion is caused and influenced by a factor of five factors, including the type of soil (erodibility), topography (slope), climate, vegetation, and soil management factors. To determine the amount of erosion on the surface of the watershed can be performed quantitatively in several ways, one using the empirical method USLE [10].

\section{Conclussion}

This study applied a fuzzy logic approach to develop erosion risk map based on geographic information system. The result of the erosion risk map was classified as very low to height. While the value of very low index was stated in between 1.01-4.0 and the height value was in between 4.01-10. It was identified that the dominant area prone to erosion risks was $68.54 \%$ of the total watershed area. The level of high erosion risk classification was approximately $28.84 \%$ of the watershed area and very low level was $2.61 \%$. These results matched the soil erodibility classes $(\mathrm{K})$. Hence, this result finding is considered valid. The classification of the soil erodibility $(\mathrm{K})$ were as follow, very low $(0.0$ 10. I.W. Sutapa, Jurnal SMARTek, 8, 169-181 (2010)
$-0.10)$, moderate (0.21-0.32), height (0.44-0.55) and very high $(0.56-0.64)$.

The author would like to thank the Directorat General of Higher Education, Ministry of Research, Technology and Higher Education for funding this research through grants postgraduate

\section{References}

1. M. H. Purnomo, Prospect and Apllication of Artificial Intelligent Knowledge (Inauguration speech for Professor, Institute of Sepuluh November, Indonesia, 2004)

2. D.C.S Bist, M. Pohan, M. C. Joshi,. J. Comp Modelling and New Technologies, 13, 16-23 (2009)

3. Z. Akyurek, O. Kivanç, 7th International Symposium on Spatial Accuracy Assessment in Natural Resources and Environmental Sciences, Turkey, 2010.

4. M. Amirabdollahian, A. Keyvan and M. R. Chamani, International Conference on Information and Intelligent Computin, IPCSIT, 18, Singapore, 2011

5. T.H. Gournellos, N. Evelpidou, A, Vassilopoulos. J. Natural Hazards, 31, 63-83 (2004)

6. S. Kusumadewi, Analyses and Design in Fuzzy utilizing Toolbox Matlab, (Indonesia, 2002)

7. Sutojo, Mulyanto, Suhartono, Arificial Intelligent. (Indonesia, 2011)

8. S.A. Asklany, K. Elhelow, I.K. Youssef, M.A. ElWahab, Journal Atmospheric Research, 228-236 (2011)

9. D.R. Navianti, I.G. Usadha, F.A. Widjajati. Jurnal Sains dan Seni ITS, 1, (2012) 